\title{
Kaolin-induced chronic hydrocephalus accelerates amyloid deposition and vascular disease in transgenic rats expressing high levels of human APP
}

Gerald D Silverberg ${ }^{1,4^{*}}$, Miles C Miller ${ }^{1}$, Crissey L Pascale ${ }^{1}$, llias N Caralopoulos' ${ }^{1}$ Yuksel Agca ${ }^{2}$, Cansu Agca ${ }^{2}$ and Edward G Stopa ${ }^{1,3}$

\begin{abstract}
Background: Normal pressure hydrocephalus (NPH) is most common in the elderly and has a high co-morbidity with Alzheimer's disease (AD) and cerebrovascular disease (CVD). To understand the relationship between NPH, AD and $C V D$, we investigated how chronic hydrocephalus impacts brain amyloid-beta peptide $(A \beta)$ accumulation and vascular pathology in an AD transgenic rodent model. Previously we showed that the altered CSF physiology produced by kaolin-hydrocephalus in older wild-type Sprague-Dawley rats increased A $\beta$ and hyperphosphorylated Tau (Silverberg et. al. Brain Res. 2010, 1317:286-296). We postulated that hydrocephalus would similarly affect an $A D$ rat model.

Methods: Thirty-five transgenic rats (tgAPP21) that express high levels of human APP and naturally overproduce $A \beta 40$ were used. Six- $(n=7)$ and twelve-month-old $(n=9)$ rats had hydrocephalus induced by cisternal kaolin injection. We analyzed $A \beta$ burden $(A \beta 40, A \beta 42$ and oligomeric $A \beta)$ and vascular integrity (Masson trichrome and Verhoeff-Van Gieson) by immunohistochemistry and chemical staining at 10 weeks $(n=8)$ and 6 months $(n=5)$ post hydrocephalus induction. We also analyzed whether the vascular pathology seen in tgAPP21 rats, which develop amyloid angiopathy, was accelerated by hydrocephalus. Age-matched naïve and sham-operated tgAPP21 rats served as controls $(n=19)$.

Results: In hydrocephalic tgAPP21 rats, compared to naive and sham-operated controls, there was increased Aß 40 and oligomeric $A \beta$ in hippocampal and cortical neurons at 10 weeks and 6 months post-hydrocephalus induction. No dense-core amyloid plaques were seen, but diffuse $A \beta$ immunoreactivity was evident in neurons. Vascular pathology was accelerated by the induction of hydrocephalus compared to controls. In the six-month-old rats, subtle degenerative changes were noted in vessel walls at 10 weeks post-kaolin, whereas at six months post-kaolin and in the 12-month-old hydrocephalic rats more pronounced amyloid angiopathic changes were seen, with frequent large areas of infarction noted.

(Continued on next page)
\end{abstract}

\footnotetext{
* Correspondence: geralds@stanford.edu

${ }^{1}$ Department of Neurosurgery, The Warren Alpert Medical School of Brown

University and the Aldrich Laboratories at Rhode Island Hospital, 593 Eddy Street, Providence, RI 02903, USA

${ }^{4}$ Stanford University, 710 Frenchmans Rd, Stanford, CA 94305, USA

Full list of author information is available at the end of the article
} 
(Continued from previous page)

Conclusions: Kaolin-hydrocephalus can accelerate intraneuronal A 340 accumulation and vascular pathology in tgAPP21 rats. In addition, disrupted CSF production and reduced CSF turnover results in impaired A clearance and accelerated vascular pathology in chronic hydrocephalus. The high co-morbidity seen in NPH, AD and CVD is likely not to be an age-related coincidence, but rather a convergence of pathologies related to diminished CSF clearance.

Keywords: Normal pressure hydrocephalus, Transgenic rat, Kaolin-induced hydrocephalus, Amyloid-beta peptide, Cerebrovascular disease, Amyloid angiopathy, Solute clearance, CSF circulation

\section{Background}

Normal pressure hydrocephalus (NPH) is a clinicallydiagnosed disease that presents with one or several symptoms and signs, including gait disturbance, incontinence and dementia [1]. The gait disturbance is described as a gait apraxia (magnetic gait), and the urinary incontinence is often nocturnal. There is an associated ventricular enlargement, usually involving all ventricles, and some enlargement of the subarachnoid space (SAS) over the convexities. There is usually intermittent elevation of the cerebrospinal fluid (CSF) pressure most often at night and often during rapid eye movement (REM) sleep [2-4]. Clinical diagnosis rests on clinical and radiologic findings as well as the effects of large volume CSF removal [5].

Although there is no pathological finding that confirms the clinical diagnosis of NPH on brain biopsy or at post-mortem, there is often evidence for both Alzheimer's disease (AD) and cerebrovascular disease (CVD) with a frequency that precludes the idea that these are unrelated afflictions of the elderly [6-9]. Indeed, initially these findings were thought to be simply unrelated coincidental diseases of the elderly, but that is no longer tenable.

In patients with the symptoms and signs of NPH, there is a very high co-morbidity with both $\mathrm{AD}$ and CVD. The incidence of AD pathology in patients with $\mathrm{NPH}$ is much higher than expected if the two diseases were unrelated diseases of advancing age. For instance, anywhere from $25 \%$ to $75 \%$ of $\mathrm{NPH}$ patients will have evidence of $\mathrm{AD}$ pathology, depending upon the degree of dementia, on brain biopsy at the time of shunt placement or at autopsy [10-12]. In aging, only $10 \%$ of subjects over 65 will have clinical or histological evidence of $\mathrm{AD}$ [13]. Evidence of CVD is similarly increased in NPH over normally aged subjects.

Alzheimer's disease is characterized by amyloid plaques (neuritic or dense-core), composed of amyloid-beta peptides $(A \beta)$ and neurofibrillary tangles made up of paired helical filaments of hyperphosphorylated tau protein (pTau). Amyloid angiopathy is also characteristic of AD brains. This vascular pathology is characterized by vascular deposition of $A \beta[14,15]$. In recent years it has become accepted that the accumulation of $A \beta$ in non- familial $\mathrm{AD}$ is due to an inability to clear these peptides from the brain, rather than an overproduction as seen in familial AD [16-18].

In previous reports, it was shown that both $A \beta$ and pTau protein accumulated in older (12 months) wildtype Sprague-Dawley rats, rendered hydrocephalic by intra-cisternal injection of kaolin, in concentrations significantly higher than age-matched and sham-operated controls $[19,20]$. In this histological and immunohistochemical study we report the effects of induced hydrocephalus on a transgenic rat model of AD (tgAPP21): a double transgenic ( $S w /$ Ind mutant) human amyloid precursor protein (APP) construct that expresses high levels of human APP and A $\beta 40$ [21]. Our hypothesis was that if the CSF was not an important clearance pathway for $A \beta$ removal from the brain, then the accumulation of $A \beta$ would be the same between hydrocephalic and control $\operatorname{tgAPP} 21$ rats. We found that the hydrocephalic tgAPP21 rats accumulated $A \beta 40$ and oligomeric $A \beta$, as well as manifesting evidence of vascular disease and ischemic infarction, well before age-matched and shamoperated controls. Cortical infarction was seen only in the hydrocephalic rats.

\section{Methods \\ Animals}

Breeding pairs of APP 21 transgenic rats (tgAPP21) were obtained from the Department of Veterinary Pathobiology at the University of Missouri. These rats express high levels of human APP and naturally overproduce $\mathrm{A} \beta 40$, but not $\mathrm{A} \beta 42$. The tgAPP21 rats were produced from inbred Fischer 344 rats that express human APP driven by the ubiquitin- $C$ promoter. They were generated via lentiviral vector infection of the Fischer $344 \mathrm{zy}-$ gotes [21]. Immunohistochemistry in brain showed that the human APP transgene was expressed in neurons, but not in glial cells. After quarantine, the tgAPP21 rats were allowed to breed normally. The rats were housed in the veterinary care facility of the Aldrich Laboratories at Rhode Island Hospital and had food and water ad lib. All experiments were approved by the Institutional Animal Care and Use Committee (IACUC) at Rhode Island Hospital. 
Hydrocephalus was induced by cisternal injection of kaolin (aluminum silicate $0.9 \%$ ). The technique has been previously published $[19,20,22]$. Thirty-five tgAPP21 rats were used in these studies. Six-month $(n=7)$ and twelve-month-old $(n=9)$ rats had hydrocephalus induced by cisternal kaolin injection. After 10 weeks or six months of hydrocephalus the rats were euthanized by intra-peritoneal pentobarbital injection $(125 \mathrm{mg} / \mathrm{kg})$. Age-matched naïve and sham-operated tgAPP21 rats served as controls $(n=19)$ and their brains were processed in exactly the same way. Three of the 12-monthold hydrocephalic rats and four of the controls were allowed to survive to a natural death to assess the effects of the vascular changes on brain parenchyma (see Table 1).

After intracardiac cannulation and perfusion with phosphate-buffered saline, the brains were removed and immersed in $4 \%$ paraformaldehyde. Following standard tissue processing and paraffin embedding procedures, coronal brain sections were serially cut at $8 \mu \mathrm{m}$ starting from the level of the median eminence. Ventricular enlargement was measured by the Evans ratio for control rats compared to rats at 10 weeks post hydrocephalus induction. The maximum ventricular diameter on coronal section at the bregma was divided by the maximum brain diameter on the post-mortem brain sections.

We analyzed $A \beta$ burden by immunohistochemistry $(\mathrm{A} \beta 40, \mathrm{~A} \beta 42$ and oligomeric $\mathrm{A} \beta)$, and vascular integrity by histochemical staining (Masson trichrome and Verhoeff-Van Gieson) at 10 weeks $(n=8)$ and six months $(n=5)$ post hydrocephalus induction. We also analyzed whether the vascular pathology seen in tgAPP21 rats, which normally develop amyloid angiopathy, was accelerated by hydrocephalus. Age-matched naive and sham-operated tgAPP21 rats served as controls $(\mathrm{n}=15)$.

\section{Immunohistochemistry}

Eight $\mu \mathrm{m}$-thick tissue sections (on poly-L-lysine-coated slides) were incubated in an oven at $60^{\circ} \mathrm{C}$ for 1 hour, and after deparaffinization and rehydration, sections were treated with hot $\left(85^{\circ} \mathrm{C}\right) 10 \mathrm{mM}$ citrate buffer, $\mathrm{pH} 6$, for 15 minutes. Sections were washed with distilled water and then quenched with a dual endogenous enzymeblocking reagent (Dako, Carpinteria, CA, USA; Catalog \#S2003) for 10 minutes at room temperature to eliminate endogenous peroxidase activity. After washing in 0.05 M Tris-buffered saline with $0.05 \%$ Tween-20 (TBST), pH 7.6, sections were incubated overnight at $4^{\circ} \mathrm{C}$ with rabbit polyclonal antibodies directed against A 340 (Alpha Diagnostic International, San Antonio, TX, USA; Catalog \#BAM401-A, diluted 1:100), A $\beta 42$ (Alpha Diagnostic International; Catalog \#BAM421-A, diluted 1:200), or oligomeric A $\beta$ (A11; Chemicon, Temecula, CA, USA; Catalog \#AB9234, diluted 1:2000). After washing the sections in TBST, a horseradish peroxidase

Table 1 Summary of experimental animals and histological findings

\begin{tabular}{|c|c|c|c|c|c|c|c|c|c|}
\hline Duration & Group & $\mathbf{N}$ & $\begin{array}{c}\text { Ventricular } \\
\text { Enlargement }\end{array}$ & $\begin{array}{c}\text { Histiocytic \& } \\
\text { Granulomatous } \\
\text { Inflammation }\end{array}$ & $\begin{array}{c}\text { Neuronal } \\
A \beta 40\end{array}$ & $\begin{array}{c}\text { Neuronal } \\
\text { A } \beta 42\end{array}$ & $\begin{array}{c}\text { Neuronal } \\
\text { Oligomeric } A \beta\end{array}$ & $\begin{array}{c}\text { Vascular } \\
\text { Pathology }\end{array}$ & $\begin{array}{l}\text { Ischemic } \\
\text { Infarcts }\end{array}$ \\
\hline $6 \mathrm{mo} .+10 \mathrm{wk}$ & Kaolin & 4 & ++ & +++ & ++ & - & ++ & ++ & - \\
\hline $6 \mathrm{mo} .+10 \mathrm{wk}$ & Sham & 2 & - & - & + & - & + & + & - \\
\hline 6 mo. + 10 wk. & Naïve & 2 & - & - & + & - & + & + & - \\
\hline $6 \mathrm{mo} .+6 \mathrm{mo}$ & Kaolin & 3 & + & + & ++ & - & +++ & ++ & - \\
\hline $6 \mathrm{mo} .+6 \mathrm{mo}$ & Sham & 2 & - & - & + & - & ++ & + & - \\
\hline $6 \mathrm{mo} .+6 \mathrm{mo}$ & Naïve & 2 & - & - & + & - & ++ & + & - \\
\hline 12 mo. + 10 wk. & Kaolin & 4 & ++ & +++ & ++ & - & +++ & +++ & - \\
\hline 12 mo. + 10 wk. & Sham & 2 & - & - & + & - & ++ & + & - \\
\hline 12 mo. + 10 wk. & Naïve & 2 & - & - & + & - & ++ & + & - \\
\hline $12 \mathrm{mo} .+6 \mathrm{mo}$ & Kaolin & 2 & + & + & +++ & - & +++ & +++ & + \\
\hline $12 \mathrm{mo} .+6 \mathrm{mo}$ & Sham & 2 & - & - & + & - & ++ & + & - \\
\hline $12 \mathrm{mo} .+6 \mathrm{mo}$ & Naïve & 1 & - & - & + & - & ++ & + & - \\
\hline $\begin{array}{l}12 \text { mo. to natural } \\
\text { end-of-life }\end{array}$ & Kaolin & 3 & + & + & +++ & - & +++ & +++ & ++ \\
\hline $\begin{array}{l}12 \text { mo. to natural } \\
\text { end-of-life }\end{array}$ & Sham & 2 & - & - & + & - & ++ & ++ & - \\
\hline $\begin{array}{l}12 \text { mo. to natural } \\
\text { end-of-life }\end{array}$ & Naïve & 2 & - & - & + & - & ++ & ++ & - \\
\hline
\end{tabular}

The pathology and morphological changes, as observed in histochemically-stained sections, were qualitatively graded using a scale ranging from no detectable changes $(-)$ to mild $(+)$, moderate $(++)$, or severe $(+++)$ changes. 
(HRP)-labeled polymer conjugated with secondary antibodies (anti-rabbit; Dako; Catalog \#K4002) was applied for 30 minutes at room temperature, in accordance with the EnVision + System for immunohistochemical staining. The tissue sections were washed in TBST and then the immunoreaction product was developed using 3,3-diaminobenzidine (Dako; Catalog \#K3468) as the chromogen. Sections were dehydrated through a series of graded alcohols back to xylene, and then coverslipped and sealed using Cytoseal XYL (Richard-Allan Scientific, Kalamazoo, MI, USA; Catalog \#8312-4). Primary antibody omission controls were run alongside the other samples to check for non-specific binding due to the secondary antibodies, and advanced AD human prefrontal cortical sections were run as positive controls. In place of using a counterstain on immunohistochemicallystained slides, adjacent serial sections were stained with hematoxylin and eosin $(\mathrm{H} \& \mathrm{E})$ for analysis of general tissue morphology.

\section{Immunofluorescence}

Following deparaffinization and rehydration, tissue sections were treated with hot $\left(85^{\circ} \mathrm{C}\right) 10 \mathrm{mM}$ citrate buffer, $\mathrm{pH}$ 6, for 15 minutes. Sections were washed with distilled water and then quenched with a dual endogenous enzyme-blocking reagent (Dako) for 10 minutes at room temperature. After washing in TBST, sections were blocked with $5 \%$ normal goat serum (Vector Laboratories, Burlingame, CA, USA; Catalog \#S-1000) for 2 hours at room temperature, and then dually incubated overnight (at $4^{\circ} \mathrm{C}$ ) with the following primary antibodies: a mouse monoclonal antibody directed against NeuN (A60; Abcam, Cambridge, MA, USA; Catalog \#ab77315, diluted 1:1000) and a rabbit polyclonal antibody directed against oligomeric $\mathrm{A} \beta$ (A11; Chemicon, diluted 1:2000). Sections were then washed in TBST, and the secondary antibodies were applied for 90 minutes at room temperature in the dark: AlexaFluor 488 goat antimouse IgG (Molecular Probes, Eugene, OR, USA; Catalog \#A-11001, diluted 1:1000) and AlexaFluor 594 goat antirabbit IgG (Molecular Probes; Catalog \#A-11012, diluted 1:1000). To eliminate possible lipofuscin autofluorescence, tissue sections were incubated in a $0.3 \%$ Sudan Black B (Sigma-Aldrich, St. Louis, MO, USA; Catalog \#S-0395) solution in 70\% ethanol for 20 minutes at room temperature in the dark. Sections were washed in distilled water and coverslipped using Vectashield Hard Set Mounting Medium with DAPI (Vector Laboratories; Catalog \#H-1500). Primary antibody omission controls were run alongside the other samples to check for nonspecific binding due to the secondary antibodies, and advanced $\mathrm{AD}$ human prefrontal cortical sections were run as positive controls.

\section{Masson trichrome staining}

Masson trichrome staining was carried out in accordance with well-characterized protocols [23,24]. Briefly, tissue sections were deparaffinized and hydrated in distilled water prior to a 1-hour treatment in Bouin's fixative (Richard-Allan Scientific; Catalog \#NC9674780) at $56^{\circ} \mathrm{C}$. Sections were washed in running distilled water until clear, and then stained in Weigert's iron hematoxylin (Richard-Allan Scientific; Catalog \#NC9231529) for 10 minutes. Following a 10-minute wash in running water, sections were stained in Biebrich scarlet-acid fuchsin (Richard-Allan Scientific; Catalog \#NC9424144) for 2 minutes. Sections were rinsed in distilled water followed by a 10-minute differentiation in phosphomolybdicphosphotungstic acid (Richard-Allan Scientific; Catalog \#NC9443038). Aniline blue (Richard-Allan Scientific; Catalog \#NC9684104) was used as a counterstain for 10 minutes, and then sections were differentiated in $1 \%$ acetic acid for 3 minutes. Sections were dehydrated through a series of graded alcohols back to xylene, and then coverslipped and sealed using Cytoseal XYL (RichardAllan Scientific).

\section{Verhoeff-Van Gieson staining}

The Verhoeff-Van Gieson staining protocol for elastic fibers was performed using well-established protocols $[24,25]$. Briefly, tissue sections were deparaffinized and hydrated to distilled water followed by a1-hour incubation in Verhoeff's working solution (Polysciences, Warrington, PA, USA; Catalog \#25089). Sections were rinsed in running water, and then differentiated in $2 \%$ ferric chloride (Sigma-Aldrich; Catalog \#451649) for 2 minutes. Following a 10-minute wash in running water, sections were treated with $5 \%$ aqueous sodium thiosulfate (Sigma-Aldrich; Catalog \#S7026) for 1 minute. Tissue sections were then washed in running water for 5 minutes, and counterstained with Van Gieson's solution (Poly Scientific, Bay Shore, NY, USA; Catalog \#s289) for 3 minutes. Sections were quickly dehydrated through a series of graded alcohols back to xylene, and then coverslipped and sealed using Cytoseal XYL (Richard-Allan Scientific).

\section{Microscopy, image acquisition \& qualitative grading}

All immunohistochemistry and histochemically-stained slides were converted to digital images using Aperio Scan Scope (Aperio Technologies, Vista, CA, USA) as 8-bit acquisitions of color. For confocal microscopy, images were acquired with a Nikon C1si confocal microscope (Nikon Inc., Melville, NY, USA) using $488 \mathrm{~nm}$ and $561 \mathrm{~nm}$ diode lasers. Serial optical sections were performed with EZ-C1 computer software (Nikon Inc.). Zseries sections were collected at $1.5 \mu \mathrm{m}$ with a $20 \times$ PlanApo lens and scan zoom of $2 \times$. Each wavelength 
was acquired separately by invoking frame lambda, and images were processed with Elements computer software (Nikon Inc.). Pathology and morphological changes, as observed in histochemically-stained sections, were qualitatively graded using a scale ranging from no detectable changes $(-)$, to mild $(+)$, moderate $(++)$, or severe $(+++)$ changes.

\section{Results}

All histological and immunohistochemical findings are summarized in Table 1. The tgAPP21rats injected with kaolin developed hydrocephalus similar to that reported in our wild-type Sprague-Dawley rats [20]. Evans index of ventricular size in the hydrocephalic tgAPP21 rats was significantly larger than controls and was similar to what we previously reported [10 weeks $0.30 \pm 0.04$ compared to sham-operated controls $0.19 \pm 0.02$ $($ mean $\pm \mathrm{SD})$ ]. Figure 1 compares the ventricular and aqueductal morphological changes observed in a typical hydrocephalic tgAPP21 rat to a typical age-matched shamoperated control.

The hydrocephalus was due to an intense histiocytic and granulomatous reaction in the SAS which was largely resolved by six months, though some small granulomas remained. Despite the resolution of the inflammation, scarring and blockage of the SAS remained (Figure 2).

$A \beta$ immunostaining showed a marked increase in intraneuronal $\mathrm{A} \beta 40$ in the hippocampus and frontoparietal cortex compared to sham-operated controls (Figure 3). No amyloid plaques were observed, but diffuse cytoplasmic A $\beta 40$ immunoreactivity was evident across multiple neuronal populations. The absence of dense-core plaques was not surprising given the absence of $\mathrm{A} \beta 42$ accumulation.

Although A $\beta 42$ is more apt to self-assemble, $A \beta 40$ can also self-assemble into oligomeric forms. Oligomeric $A \beta$ immunoreactivity was predominately confined to neurons
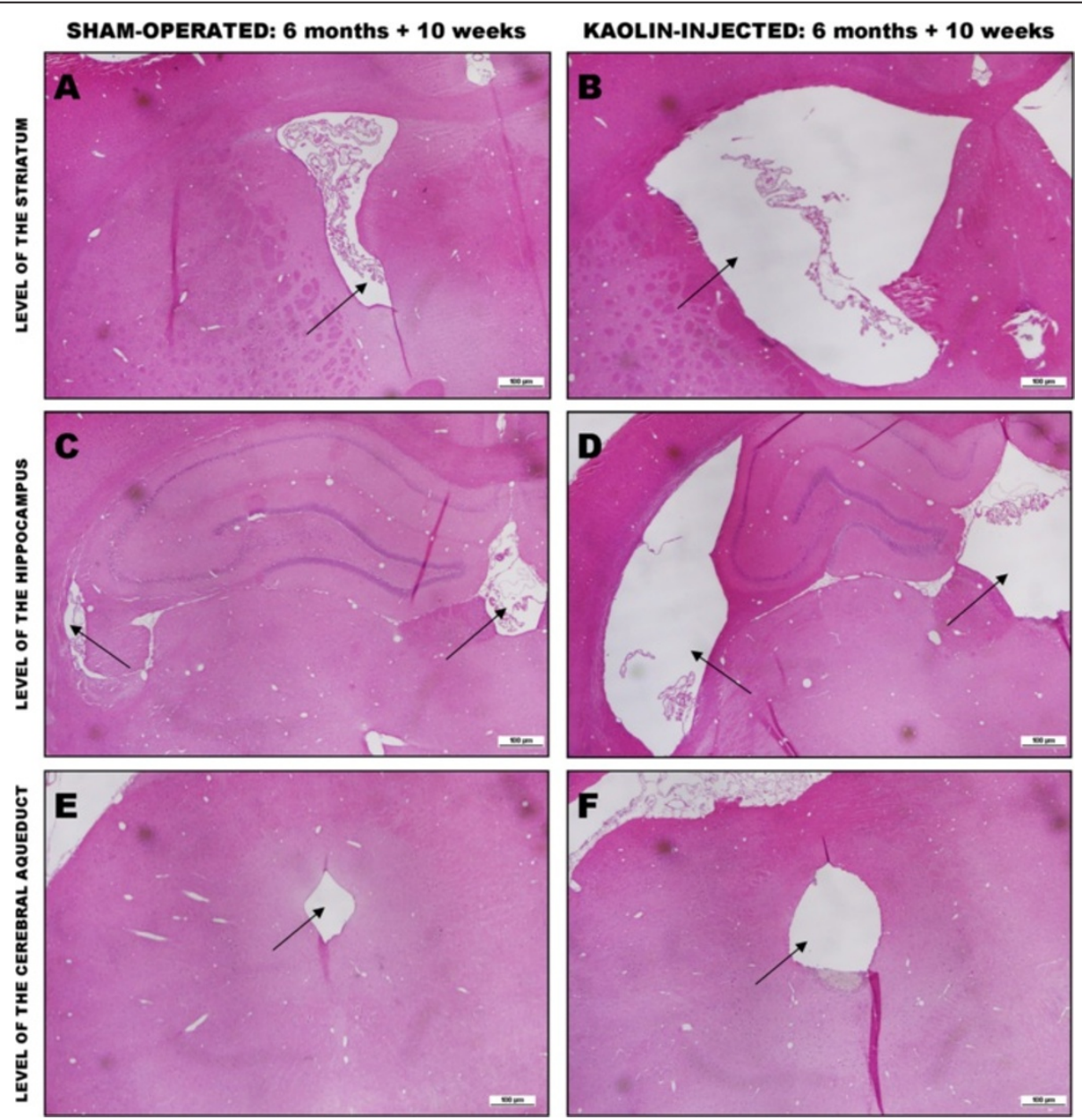

Figure 1 Sections of sham-operated and kaolin-injected rats 10 weeks after injection. Comparison of a representative sham-operated tgAPP21 rat (left panels) to a representative kaolin-injected tgAPP21 rat (right panels) at three different coronal brain levels: the level of the striatum (A \& B), the level of the hippocampus (C \& D), and the level of the cerebral aqueduct (E \& F). Note the marked ventricular and aqueductal enlargement in the kaolin-treated tgAPP21 rat compared to sham-operated rat (arrows). H\&E stain, $\times 10$. 

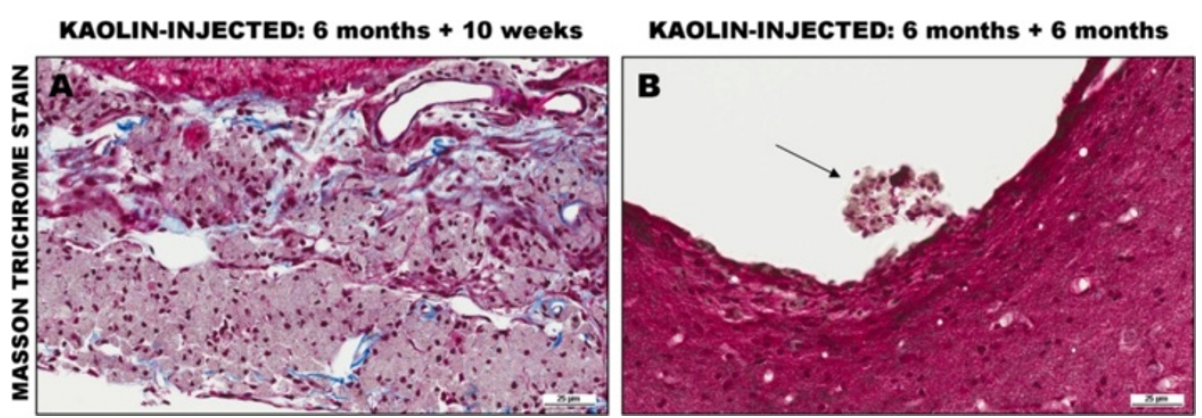

Figure 2 Effects of cisternal kaolin injection. (A) At 10 weeks post-kaolin injection, there is marked histiocytic and granulomatous inflammation composed of many macrophages filled with kaolin in the SAS at the base of the brain (here around the hypothalamus and 3rd ventricle). (B) At six months post-kaolin injection, the inflammation has subsided leaving scarring and blockage in the SAS (below the 3rd ventricle) and a few small collections of histiocytes in the ventricle walls, here the 3rd ventricle (arrow). Masson trichrome stain, $\times 200$.

in both the hippocampus and frontoparietal cortex of tgAPP21 rats (Figure 4).

In hydrocephalic tgAPP21 rats, compared to controls, there was increased oligomeric $A \beta$ immunoreactivity in addition to the increase in $A \beta 40$ in both hippocampal (data not shown) and cortical neurons at 10 weeks posthydrocephalus induction in 6 and 12-month-old animals (Figure 5).

Vascular pathology was accelerated by the induction of hydrocephalus compared to controls. In the six-monthold rats, subtle degenerative changes were noted in vessel walls at 10 weeks post-kaolin, whereas in the six- month-old rat at six months post-kaolin and in the 12month-old rat 10 weeks post-kaolin, more pronounced degenerative changes were seen with clear expansion of the Virchow-Robin space in interstitial vessels (Figure 6).

Amyloid angiopathic changes were seen by immunostaining for $A \beta 40$. These changes were more dramatic in the 12-month-old tgAPP21 rats than in the six-monthold rats, and in both sets of hydrocephalic rats, the difference from sham-operated controls was clearly evident (Figure 7).

Seven of the tgAPP21 rats were allowed to reach their natural end of life (approximately 30 months). Three

SHAM-OPERATED: 6 months + 10 weeks
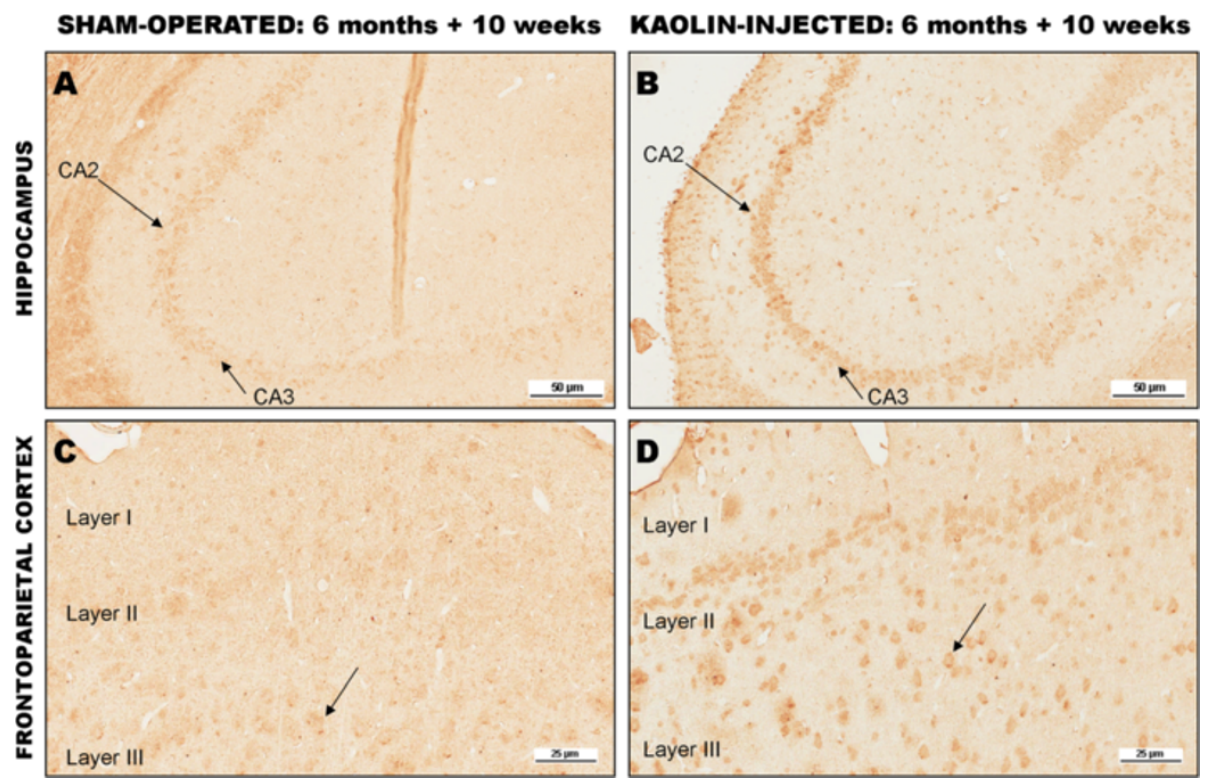

Figure $3 \mathbf{~ I m m u n o h i s t o c h e m i c a l ~ s t a i n i n g ~ f o r ~ A ~} \mathbf{3 4 0}$. (A) Hippocampal neurons in a sham-operated six-month-old tgAPP21 rat (arrows). There is minimal immunoreactivity evident 10 weeks after sham-surgery, x80. (B) Hippocampal neurons in a hydrocephalic six-month-old tgAPP21 rat 10 weeks after kaolin injection demonstrating enhanced immunoreactivity in areas CA2 and CA3 (arrows), $\times 80$. (C) Frontoparietal cortical neurons (arrow) in a sham-operated six-month-old tgAPP21 rat at 10 weeks post-surgery showing minimal A 40 immunoreactivity, $\times 200$ (D) There is more robust neuronal immunoreactivity in the frontoparietal cortex in six-month-old tgAPP21 rats 10 weeks following kaolin injection (arrow), $\times 200$. 


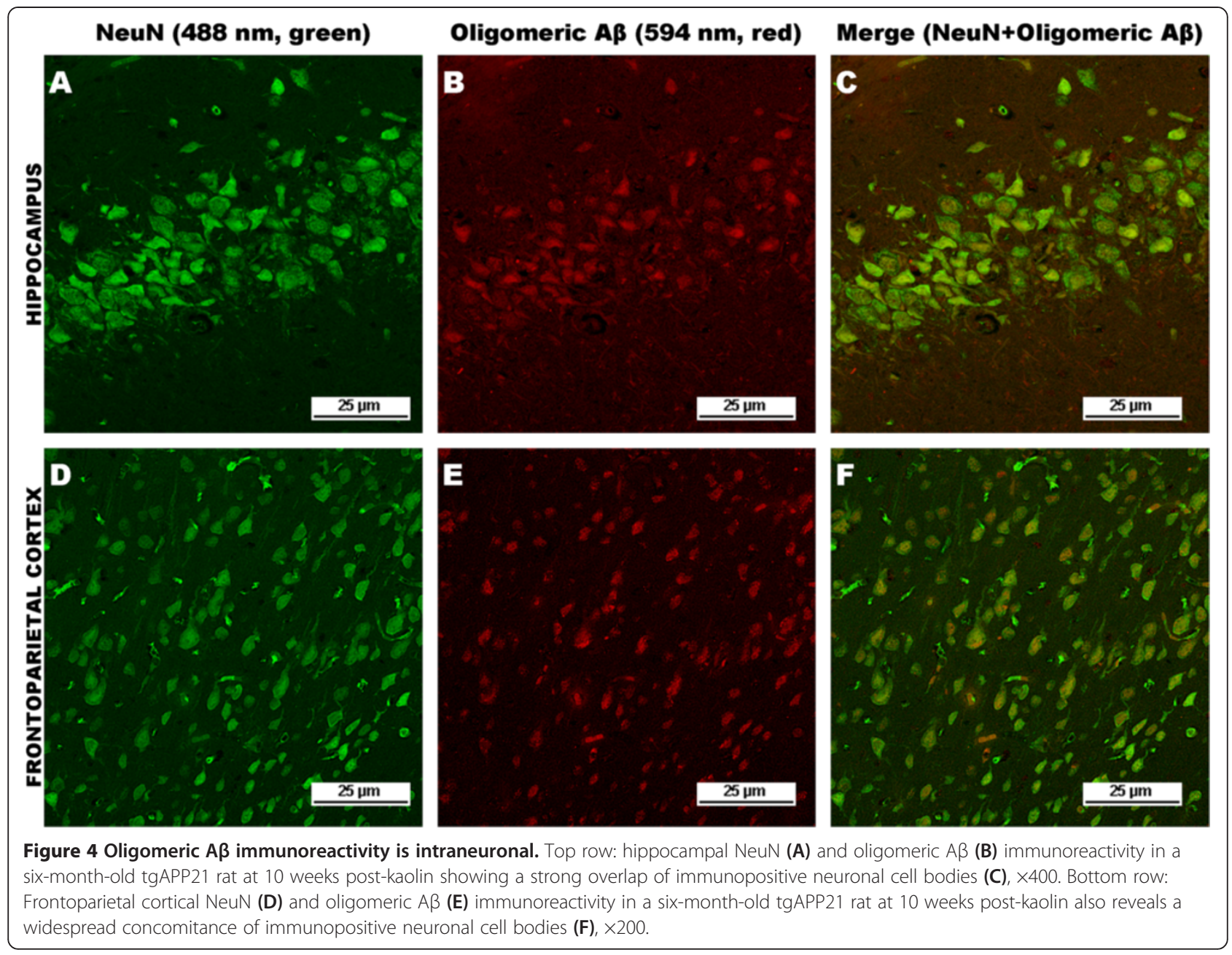

hydrocephalic rats were compared to four controls. The hydrocephalic tgAPP21 rats were found to have frequent areas of microscopic cortical infarction in their brains (Figure 8). In the non-kaolin controls, no infarcts were seen.

\section{Discussion}

Clearance of macromolecules, such as $A \beta$, from the brain interstitial space involves at least four different pathways: i) via in situ degradation [26-30], ii) active transport across the blood-brain barrier [31-36], iii) across the choroid plexus epithelium by active transport [37], and iv) via the production and turnover of the CSF. CSF turnover is defined as the number of times the CSF is renewed in 24 hours and is calculated by dividing CSF production in 24 hours by the volume of the CSF space [38-42]. Normally in humans, CSF turnover occurs $4-5$ times per day.

Hydrocephalus is known to disrupt normal CSF physiological functions. In both $\mathrm{AD}$ and in hydrocephalic patients,
CSF turnover is reduced threefold [6,43,44]. In both wildtype rat models of NPH and in human NPH patients therefore, CSF clearance of potentially toxic solutes like $A \beta$ is significantly reduced, resulting in the accumulation of these molecules in brain parenchyma. Several investigations in laboratory animals have described significantly decreased CSF production and turnover after kaolin hydrocephalus induction [45,46], and is also seen in humans with NPH [44]. Resistance to CSF absorption is also increased in hydrocephalus $[47,48]$. Despite eventual clearance of the inflammation produced by the kaolin, increased resistance to CSF absorption and decreased compliance remain $[47,48]$.

This study examined the effects of kaolin-induced hydrocephalus on amyloid accumulation and vascular pathology in a transgenic rat model of AD. The analysis was carried out by qualitative histological and immunohistochemical staining, comparing the hydrocephalic tgAPP21 brains to age-matched, sham-operated and naïve controls. We found that induced hydrocephalus accelerated $A \beta$ accumulation in neurons and $A \beta$ 

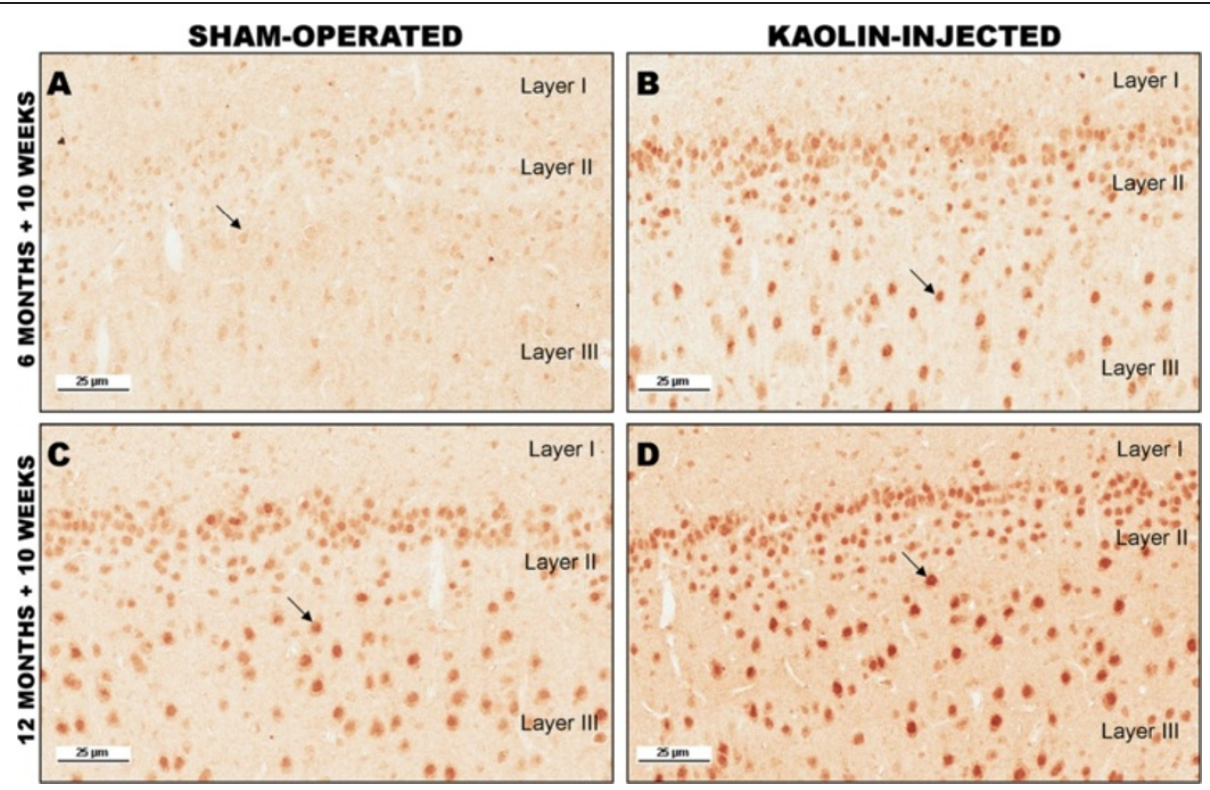

Figure 5 Oligomeric $A \beta$ in tgAPP21 hydrocephalic rat frontoparietal cortex compared to control rat (arrows). Top row: six-month-old rat. (A) sham-operated control brain showing minimal immunostaining for oligomeric forms, $\times 200$. (B) six-month-old rat 10 weeks post-kaolin hydrocephalus, $\times 200$. There is a marked increase in immunoreactive product. Bottom row: 12 -month-old rat. (C) sham-operated control showing moderate immunoreactivity for oligomeric $A \beta, \times 200$. (D) 12-month-old rat 10 weeks post-kaolin hydrocephalus showing a significant increase in oligomeric $A \beta, \times 200$

deposition in the cerebral vasculature, presumably due to decreased clearance of $A \beta$. A $\beta$ immunostaining in cerebral cortex and hippocampus was increased in the hydrocephalic rats compared to controls, and amyloid angiopathic degeneration of cerebral vessels was also accelerated compared to controls. The amyloid angiopathy associated with the hydrocephalic rats appeared to cause microscopic ischemic infarcts not seen in the control animals.

It is well known that there is variability in the degree of hydrocephalus produced by intracisternal kaolin. Also in any qualitative histological and immunohistochemical study, fixation artifact must always be considered in assessing changes. Therefore, comparison to both sham-operated and naïve controls processed in exactly the same way as the hydrocephalic rats, is essential to identifying true differences from artifact. The microscopic findings in the two groups (hydrocephalic and controls) in this study were internally consistent but were strikingly different in $A \beta$ accumulation, self-assembly into oligomeric forms and vascular pathology. Although not quantitative, the group comparisons were sufficiently

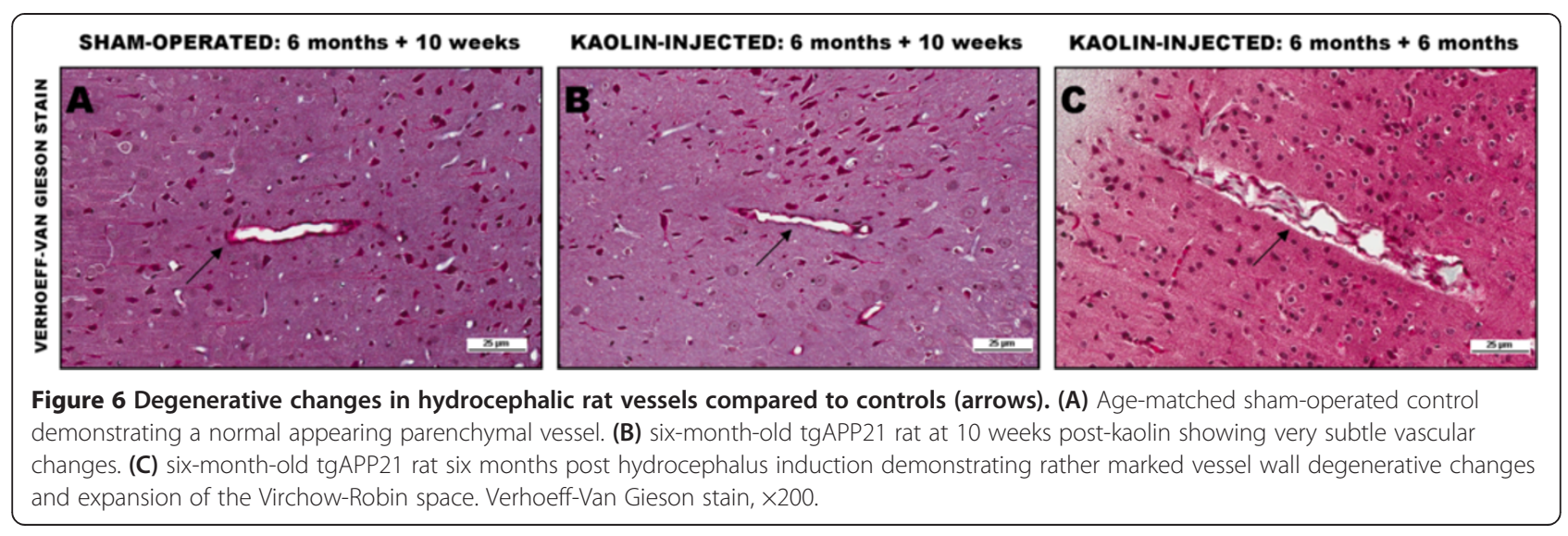



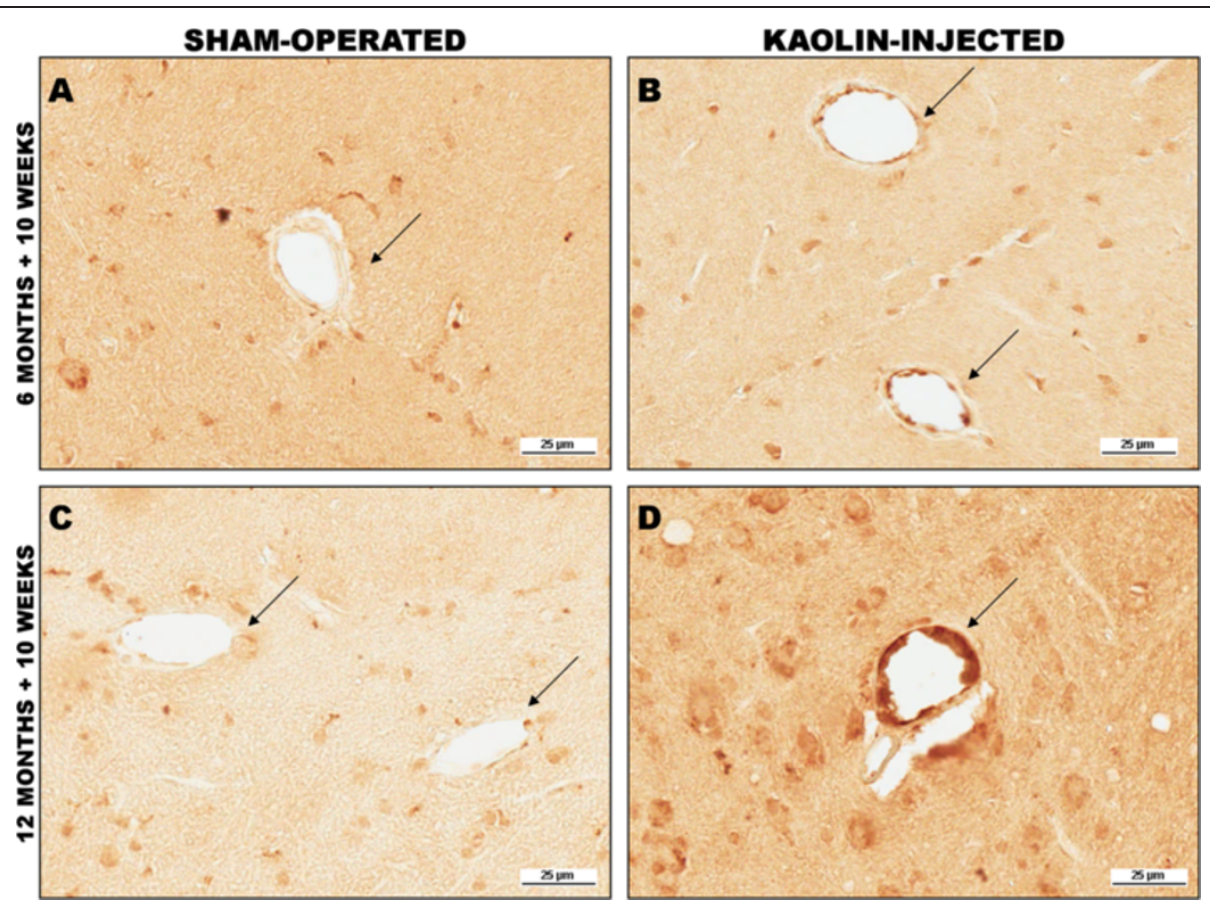

Figure 7 Deposition of A $\mathbf{B} 40$ in brain parenchymal vessels (arrows). Top row: six-month-old tgAPP21 rat. (A) sham-operated age-matched control, x200. (B) Hydrocephalic tgAPP21 rat 10 weeks post kaolin injection, $\times 200$. Note a moderate increase in immunoreactivity in the vessels of the hydrocephalic rat compared to control. Bottom row: 12-month-old tgAPP21 rat. (C) Age-matched, sham-operated control showing minimal vascular A $\beta$ immunostaining, x200. (D) 12-month-old tgAPP21 rat 10 weeks after hydrocephalus induction showing marked deposition of AB in vessel walls, $\times 200$.

different to conclude that accelerated amyloid deposition and vascular pathology occurs in tgAPP21 rats with kaolin-induced hydrocephalus.

One can argue that the tgAPP21 rat is more a model for amyloid angiopathy [49] rather than $\mathrm{AD}$, in that there is no increase in $A \beta 42$ concentrations and no amyloid plaque formation was evident. Instead we see that the predominantly expressed A $\beta 40$ accumulates

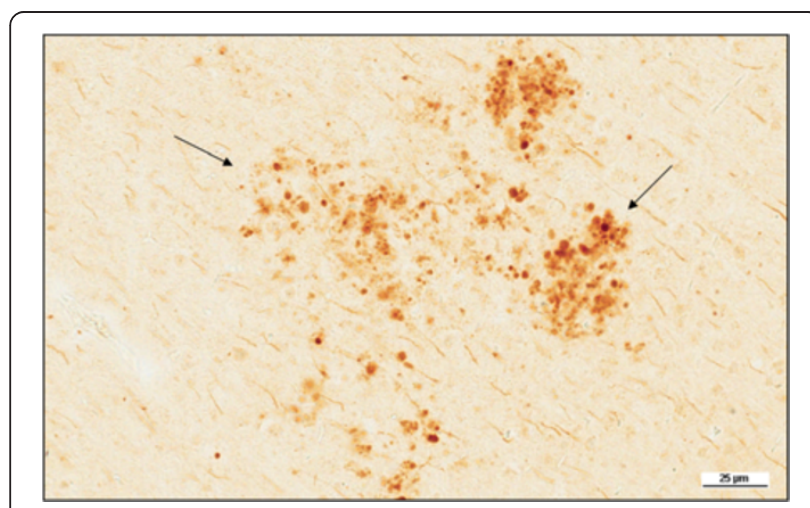

Figure 8 Evidence of cortical infarcts in hydrocephalic tgAPP21 rats. Frontoparietal cortex stained for $A \beta 40$. Arrows point to areas of infarction, $\times 200$. in the cerebral microvessels, reportedly localized to the basement membrane [50,51]. However, our study was meant to explore whether the CSF plays a significant role in the clearance of macromolecular solutes from the brain interstitial space, and whether its failure in chronic hydrocephalus accelerates the accumulation of many brain metabolites. The present study suggests that this is the case in rats and likely in humans as well.

\section{Conclusions}

The results of this study underscore the importance of normal CSF physiologic functions in clearing potentially toxic macromolecules from the brain. The study shows that kaolin-induced hydrocephalus can accelerate intraneuronal $A \beta$ accumulation and self-assembly, and accelerate vascular pathology in tgAPP21 rats. In addition, it demonstrates that disrupted CSF production and turnover results in impaired $A \beta$ clearance from the brain and accelerates vascular pathology in chronic hydrocephalus. The high co-morbidity seen in $\mathrm{NPH}, \mathrm{AD}$ and CVD is likely not an age-related coincidence, but rather a convergence of pathologies related to reduced solute clearance. 


\section{Abbreviations}

Aß: Amyloid-beta peptide; AD: Alzheimer's disease; APP: Amyloid precursor protein; CSF: Cerebrospinal fluid; CVD: Cerebrovascular disease;

H\&E: Hematoxylin and eosin; HRP: Horseradish peroxidase;

IACUC: Institutional Animal Care and Use Committee; NPH: Normal pressure hydrocephalus; pTau: Hyperphosphorylated tau protein; REM: Rapid eye movement; SAS: Subarachnoid space; TBST: 0.05 M Tris-buffered saline with 0.05\% Tween-20; tgAPP21: Double mutant APP $_{\text {sw/lnd }}$ transgenic rat line.

\section{Competing interests}

The authors declare that they have no competing interests.

\section{Authors' contributions}

GDS conceived the research project and wrote the first draft of the paper EGS and MCM did the histological studies and the interpretation of the results. CLP and INC did the cisternal kaolin injections and cared for the rats until sacrificed. YA and CA provided the tgAPP21 breeding pairs. All authors contributed to the writing and editing of the manuscript and agree with its contents and conclusions.

\section{Acknowledgements}

The authors would like to thank Virginia Hovanesian for aid in microscopy/ image acquisition, and Paul Monfils, Catherine Chiu and Doreen P. Osgood, PhD for their technical assistance. We also thank Dr. Petra Klinge for development of the kaolin-hydrocephalus protocol and for teaching the lab how to do it. Funding for this study was provided by the Saunders Family Fund at the Neurosurgery Foundation, Rhode Island Hospital, and the Warren Alpert Medical School of Brown University.

\section{Author details}

'Department of Neurosurgery, The Warren Alpert Medical School of Brown University and the Aldrich Laboratories at Rhode Island Hospital, 593 Eddy Street, Providence, RI 02903, USA. '2Department of Veterinary Pathobiology, University of Missouri College of Veterinary Medicine, Columbia, MO 65211, USA. ${ }^{3}$ Department of Pathology (Neuropathology), Warren Alpert Medical School of Brown University and the Aldrich Laboratories at Rhode Island Hospital, 593 Eddy Street, Providence, RI 02903, USA. “Stanford University, 710 Frenchmans Rd, Stanford, CA 94305, USA.

\section{Received: 30 October 2014 Accepted: 14 January 2015}

Published: 24 January 2015

\section{References}

1. Hakim S, Adams RD. The special clinical problem of symptomatic hydrocephalus with normal cerebrospinal fluid pressure. Observations on cerebrospinal fluid hydrodynamics. J Neurol Sci. 1965;2:307-27.

2. Symon L, Dorsch NW. Use of long-term intracranial pressure measurement to assess hydrocephalic patients prior to shunt surgery. J Neurosurg. 1975:42:258-73.

3. Symon L, Dorsch NW, Stephens RJ. Pressure waves in so-called low-pressure hydrocephalus. Lancet. 1977;2:1291-2.

4. Krauss JK, Droste DW, Bohus M, Regel JP, Scheremet R, Riemann D, et al. The relation of intracranial pressure B-waves to different sleep stages in patients with suspected normal pressure hydrocephalus. Acta Neurochir (Wien). 1995:136:195-203.

5. Wikkelsø C, Hellström P, Klinge PM, Tans JT, European iNPH Multicentre Study Group. The European iNPH Multicentre Study on the predictive values of resistance to CSF outflow and the CSF Tap Test in patients with idiopathic normal pressure hydrocephalus. J Neurol Neurosurg Psychiatry. 2013:84:562-8.

6. Silverberg GD, Mayo M, Saul T, Rubenstein E, McGuire D. Alzheimer's disease, normal-pressure hydrocephalus, and senescent changes in CSF circulatory physiology: a hypothesis. Lancet Neurol. 2003;2:506-11.

7. Silverberg GD. Normal pressure hydrocephalus (NPH): ischaemia, CSF stagnation or both. Brain. 2004;127:947-8.

8. Tullberg M, Hultin L, Ekholm S, Månsson JE, Fredman P, Wikkelsø C. White matter changes in normal pressure hydrocephalus and Binswanger disease: specificity, predictive value and correlations to axonal degeneration and demyelination. Acta Neurol Scand. 2002;105:417-26.
9. Bateman GA. The pathophysiology of idiopathic normal pressure hydrocephalus: cerebral ischemia or altered venous hemodynamics? Am J Neuroradiol. 2008;29:198-203.

10. Del Bigio MR, Cardoso ER, Halliday WC. Neuropathological changes in chronic adult hydrocephalus: cortical biopsies and autopsy findings. Can J Neurol Sci. 1997;24:121-6.

11. Savolainen S, Paljärvi L, Vapalahti M. Prevalence of Alzheimer's disease in patients investigated for presumed normal pressure hydrocephalus: a clinical and neuropathological study. Acta Neurochir (Wien). 1999;141:849-53.

12. Golomb J, Wisoff J, Miller DC, Boksay I, Kluger A, Weiner H, et al. Alzheimer's disease comorbidity in normal pressure hydrocephalus: prevalence and shunt response. J Neurol Neurosurg Psychiatry. 2000;68:778-81.

13. Association A's. Alzheimer's disease facts and figures. Alzheimers Dement. 2014:2014(10):e47-92.

14. Braak H, Braak E. Neuropathological stageing of Alzheimer-related changes. Acta Neuropathol. 1991;82:239-59.

15. The National Institute on Aging, and Reagan Institute Working Group on Diagnostic Criteria for the Neuropathological Assessment of Alzheimer's Disease. Consensus recommendations for the postmortem diagnosis of Alzheimer's disease. Neurobiol Aging. 1997;18(4 suppl):S1-2.

16. Selkoe DJ. Toward a comprehensive theory for Alzheimer's disease. Hypothesis: Alzheimer's disease is caused by the cerebral accumulation and cytotoxicity of amyloid beta-protein. Ann NY Acad Sci. 2000;924:17-25.

17. Hardy J. A hundred years of Alzheimer's disease research. Neuron. 2006:52:3-13.

18. Mawuenyega KG, Sigurdson W, Ovod V, Munselli T, Kasten T, Morris JC, et al. Decreased Clearance of CNS $\beta$-Amyloid in Alzheimer's Disease. Science. 2010;330:1774

19. Klinge PM, Samii A, Niesken S, Brinker T, Silverberg GD. Brain amyloid accumulation in aged rats with kaolin-induced hydrocephalus. NeuroReport. 2006;17:657-60.

20. Silverberg GD, Miller MC, Machan JT, Johanson CE, Caralopoulos IN, Pascale $\mathrm{CL}$, et al. Amyloid and Tau accumulate in the brains of aged hydrocephalic rats. Brain Res. 2010;1317:286-96.

21. Agca C, Fritz JJ, Walker LC, Levey Al, Chan AWS, Lah JJ, et al. Development of transgenic rats producing human $\beta$-amyloid precursor protein as a model for Alzheimer's disease: Transgene and endogenous APP genes are regulated tissue-specifically. BMC Neurosci. 2008:9:28.

22. Klinge PM, Samii A, Muhlendyck A, Visnyei K, Meyer GJ, Walter GF, et al. Cerebral hypoperfusion and delayed hippocampal response after induction of adult kaolin hydrocephalus. Stroke. 2003;34:193-9.

23. Masson PJ. Trichrome stainings and their preliminary techniques. J Tech Meth. 1929:12:75.

24. Luna L. Manual of histological staining methods of the armed forces insitiute of pathology. 3rd ed. New York: McGraw Hill; 1968. p. 76-95.

25. Carson F. Histotechnology: a self-instructional text. 1st ed. Chicago: American Society for Clinical Pathology Press; 1990. p. 142-9.

26. Qiu WQ, Walsh DM, Ye Z, Vekrellis K, Zhang J, Podlisny MB, et al. Insulin-degrading enzyme regulates extracellular levels of amyloid beta-protein by degradation. J Biol Chem. 1998;273:32730-8.

27. Iwata N, Tsubuki S, Takaki Y, Watanabe K, Sekiguchi M, Hosoki E, et al. Identification of the major Abeta1-42-degrading catabolic pathway in brain parenchyma: suppression leads to biochemical and pathological deposition. Nat Med. 2000;6:143-50.

28. Iwata N, Tsubuki S, Takaki Y, Shirotani K, Lu B, Gerard NP, et al. Metabolic regulation of brain Abeta by neprilysin. Science. 2001;292:1550-2.

29. Kanemitsu H, Tomiyama T, Mori H. Human neprilysin is capable of degrading amyloid beta peptide not only in the monomeric form but also the pathological oligomeric form. Neurosci Lett. 2003;350:113-6.

30. Zlokovic BV, Yamada S, Holtzman D, Ghiso J, Frangione B. Clearance of amyloid beta-peptide from brain: transport or metabolism? Nat Med. 2000;6:718-9.

31. Shibata M, Yamada S, Kumar SR, Calero M, Bading J, Frangione B, et al. Clearance of Alzheimer's amyloid-ss(1-40) peptide from brain by LDL receptor-related protein-1 at the blood-brain barrier. J Clin Invest. 2000;106:1489-99.

32. Deane R, Du Yan S, Submamaryan RK, LaRue B, Jovanovic S, Hogg E, et al. RAGE mediates amyloid-beta peptide transport across the blood-brain barrier and accumulation in brain. Nat Med. 2003;9:907-13.

33. Deane $\mathrm{R}$, Zlokovic BV. Role of the blood-brain barrier in the pathogenesis of Alzheimer's disease. Curr Alzheimer Res. 2007:4:191-7. 
34. Zlokovic BV. Clearing amyloid through the blood-brain barrier. J Neurochem. 2004:89:807-11.

35. Silverberg GD, Miller MC, Messier AA, Majmudar S, Machan JT, Donahue JE, et al. Amyloid deposition and influx transporter expression at the blood-brain barrier increase in normal aging. J Neuropathol Exp Neurol. 2010;69:98-108.

36. Silverberg GD, Messier AA, Miller MC, Machan JT, Majmudar S, Stopa EG, et al. Amyloid efflux transporter expression at the blood-brain barrier declines in normal aging. J Neuropathol Exp Neurol. 2010;69:1034-43.

37. Pascale CL, Miller MC, Chiu C, Boylan M, Caralopoulos IN, Gonzalez L, et al. Amyloid-beta transporter expression at the blood-cerebrospinal fluid barrier is age-dependent. Fluids Barriers CNS. 2011;8:21.

38. Davson H, Oldendorf WH. Symposium on membrane transport. Transport in the central nervous system. Proc R Soc Med. 1967;60:326-9.

39. Oldendorf $\mathrm{WH}$, Davson $\mathrm{H}$. Brain extracellular space and the sink action of cerebrospinal fluid. Measurement of rabbit brain extracellular space using sucrose labeled with carbon 14. Arch Neurol. 1967;17:196-205.

40. Rennels ML, Blaumanis OR, Grady PA. Rapid solute transport throughout the brain via paravascular fluid pathways. Adv Neurol. 1990;52:431-9.

41. Johanson CE. Ventricles and Cerebrospinal fluid. In: Conn PM, editor. Neuroscience in Medicine. Philadelphia: J.B. Lippincott Company; 1995. p. 171-96.

42. Chiu C, Miller MC, Caralopoulos IN, Worden MS, Brinker T, Gordon ZN, et al. Temporal course of cerebrospinal fluid dynamics and amyloid accumulation in the aging rat brain from three to thirty months. Fluids Barriers CNS. 2012;9:3.

43. Silverberg GD, Heit G, Huhn S, Jaffe RA, Chang SD, Bronte-Stewart H, et al, The cerebrospinal fluid production rate is reduced in dementia of the Alzheimer's type. Neurology. 2001;57:1763-6.

44. Silverberg GD, Huhn S, Jaffe RA, Chang SD, Saul T, Heit G, et al. Downregulation of cerebrospinal fluid production in patients with chronic hydrocephalus. J Neurosurg. 2002;97:1271-5.

45. Hochwald GM, Nakamura S, Camins MB. The rat in experimental obstructive hydrocephalus. Z Kinderchir. 1981;34:403-10.

46. Hochwald GM, Sahar A. Effect of spinal fluid pressure on cerebrospinal fluid formation. Exp Neurol. 1971;32:30-40.

47. Brinker T, Beck H, Klinge P, Kischnik B, Oi S, Samii M. Sinusoidal intrathecal infusion for assessment of CSF dynamics in kaolin-induced hydrocephalus. Acta Neurochir (Wien). 1998;140:1069-75.

48. Kondziella D, Ludemann W, Brinker T, Sletvold O, Sonnewald U. Alterations in brain metabolism, CNS morphology and CSF dynamics in adult rats with kaolin-induced hydrocephalus. Brain Res. 2002;927:35-41.

49. Rosen RF, Fritz JJ, Dooyema J, Cintron AF, Hamaguchi T, Lah JJ, et al. Exogenous seeding of cerebral $\beta$-amyloid deposition in $\beta$ APP-transgenic rats. J Neurochem. 2012:120:660-6.

50. Weller RO, Subash M, Preston SD, Mazanti I, Carare RO. Perivascular drainage of amyloid-beta peptides from thebrain and its failure in cerebral amyloid angiopathy and Alzheimer's disease. Brain Pathol. 2008;18:253-66.

51. Carare RO, Hawkes CA, Jeffrey M, Kalaria RN, Weller RO. Cerebral amyloid angiopathy, prion angiopathy, CADASIL and the spectrum of protein elimination-failure angiopathies (PEFA) in neurodegenerative disease with a focus on therapy. Neuropathol Appl Neurobiol. 2013;39:593-611.

doi:10.1186/2045-8118-12-2

Cite this article as: Silverberg et al:: Kaolin-induced chronic

hydrocephalus accelerates amyloid deposition and vascular disease in transgenic rats expressing high levels of human APP. Fluids and Barriers of the CNS 2015 12:2.

\section{Submit your next manuscript to BioMed Central and take full advantage of:}

- Convenient online submission

- Thorough peer review

- No space constraints or color figure charges

- Immediate publication on acceptance

- Inclusion in PubMed, CAS, Scopus and Google Scholar

- Research which is freely available for redistribution 